\title{
SAFETY FEATURES FOR TWO WHEELERS
}

\author{
Harshal Wankhede ${ }^{1}$ \\ ${ }^{1}$ L\&T Technology Services \\ E-mails: $\underline{\text { Harshal.Wankhede@LntTechservices.com }}$
}

\begin{abstract}
Rapid growth in the use of motorized two wheeled vehicles in many countries has been accompanied by increases in injuries and fatalities. Motorcyclists comprise a third of all road traffic deaths in the South-East Asia and Western Pacific Regions. Head and neck injuries are the main cause of severe injury, disability and death of motorcycle users.

The paper aims to study rider behavior and driving habits, mainly towards the use of safety gear, it also suggests a possible solution to the identified problems by means of new concepts and design modification in the vehicle. The suggested feature would help to reduce twowheeler fatalities and will give a safe vehicle to society. The paper strongly recommends to included suggested Features as a mandatory requirement for Two-wheelers approval.
\end{abstract}

\section{INTRODUCTION}

More than a million people die each year on the world's roads, and the cost of dealing with the consequences of these road traffic crashes runs to billions of dollars. Current trends suggest that by 2030 road traffic deaths will become the fifth leading cause of death unless urgent action is taken.

According WHO study report on road safety highlighted the lack of comprehensive legislation on key risk factors (speed, drink-driving, motorcycle helmets, seat-belts and child restraints) for road traffic injuries. Between 2008 and 2011, 35 countries, representing almost $10 \%$ of the world's population, passed laws to address one or more of these five key risk factors. The action taken by these countries to implement new laws indicates that - with country commitment - progress is possible. However, there has been no increase in the number of countries with adequate legislation on all five key risk factors - the 28 countries (representing $7 \%$ of the world's population) with comprehensive laws remain unchanged from the last evaluation in 2009. Other than comprehensive legislation rider behavior and awareness on importance of safety is also of key factor. [1]

Unlike car two-wheelers are more venerable to accidents and hence the safety features available in two wheeler need to be revisited. Efforts are on to improvise and introduce new safety features in two wheeler. Inbuilt safety feature in two wheeler could help in reducing number of fatalities. 


\section{CURRENT STATE OF GLOBAL LEGISLATION}

Encouraging a culture of safe road behavior that in turn achieves sustained reductions in road traffic injuries requires persistent attention. Nonetheless, many countries have, within a relatively short Timeframe, implemented and enforced effective legislation to reduce speeding and drink-driving, and increase use of motorcycle helmets, seat-belts and child restraints. Sustaining high levels of enforcement and maintaining a high perception of enforcement among the public are essential to the success of such legislative measures.

\section{0 countries, representing 77\% of the world's population, have a comprehensive helmet law covering all riders, all roads and all engine types, and apply a helmet standard. \\ How many are actually following law?}

Rapid growth in the use of motorized two wheeled vehicles (Figure 1) in many countries has been accompanied by increases in injuries and fatalities among their users. Motorcyclists comprise a third of all road traffic deaths in the South-East Asia and Western Pacific Regions, but are also increasingly represented among deaths in Africa and the Americas, which are seeing rapid increases in motorcycle use. Head and neck injuries are the main cause of severe injury, disability and death among motorcycle users. In European countries, head injuries

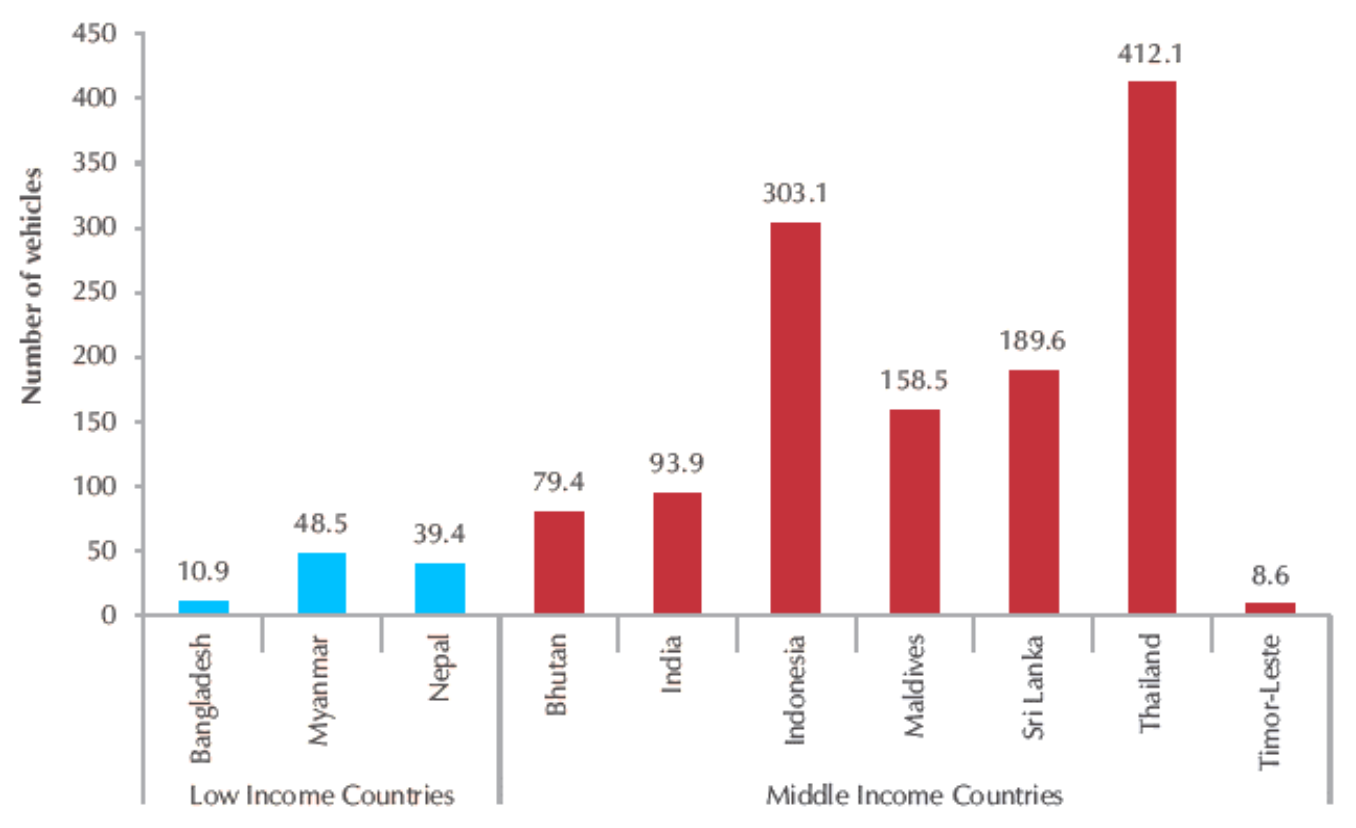

Figure 1: Number of registered vehicles per 1000 population in South-East Asia Region countries, 2013

(Source: Global status survey on road safety 2013)

contribute to approximately $75 \%$ of deaths among motorcycle users; in some low- and middle-income countries, head injuries are estimated to account for up to $88 \%$ of such fatalities. Wearing a standard, good quality motorcycle helmet can reduce the risk of death by $40 \%$ and the risk of serious injury by over $70 \%$. Introducing and enforcing legislation on helmet use is effective at increasing helmet-wearing rates and reducing head injuries. [1][2][5] 
Even though there are legislated, but enforcing this legislation is equally important, most of the South East Asian countries have legislation for motorcycle helmet law. But the study says that $50 \%$ of all fatalities were Two-wheeler rider and only $1 \%$ wearing a Helmet. [1][7][8]

This may be either because of lack of awareness among the riders or lack of disposition of law among local authority for enforcement OR both. Helmet wearing is made compulsory is some of the metropolitan cities in India but there is a need to implement same in other parts of the country

\section{TWO-WHEELER RIDING BEHAVIOR}

Major part of population (approximately 33\%) in SEA (South East Asia) region uses motorized two- wheeler as there transportation option. we have studied the behavior and driving pattern of Indian riders. Motorized two wheelers comprise more than $70 \%$ of all motor vehicles in India.

Motorcyclists along with pedestrians are among the most vulnerable road users. Speeding and risk-taking among young motorcyclists poses major public health challenge. Alarming rates of $38 \%$ of road-traffic fatalities and $51 \%$ of nonfatal road-traffic injuries involve two- ${ }^{-}$wheeler riders in India, and $75 \%$ of fatalities and $82 \%$ of non-fatal injuries occur in the age group between 15 and 44 years, while $50 \%$ of the accidents involve commuters between 20 and 30 years of age. Speeding accounts for $30 \%$ of all traffic fatalities and often involve young commuters.

The profiles of these two subgroups (SSG and NSG) were obtained in terms of sociodemographic variables (Table1), riding behaviors, and associated domains. These subgroups were comparable on Mean age $(\mathrm{t}=-0.88, \mathrm{P}=0.38)$. But, on the number of riding years, the subgroups had a statistically significant Mean difference $(\mathrm{t}=4.08, \mathrm{P}<0.001)$, which meant in a given age group greater riding years were positively associated with greater inclination to speeding. There was a significant gender difference $(\chi 2=18.37, \mathrm{P}<0.001)$, men reporting greater speeding inclination. Out of 692 male participants, 280 (46\%) reported inclination to speeding as against $69(26 \%)$ out of 269 female participants. Significant differences between the subgroups were found on domains such as motives (e.g., experience of power, relief from anger, boredom, etc.) and other factors (e.g., competing with other drivers, presence of a girl/boyfriend as pillion rider) associated with riding fast. Subgroup differences were significant also on other riding behaviors such as tendency for weaving, wheeling, lane-hopping, chasing other drivers, riding on footpath, use of cell phone while riding, and tendency for signal jumping. But on other reasons for riding faster than usual such as hurry, relief from heavy traffic, drinking, and anger or sadness of mood as trigger for riding fast the two subgroups were not significantly different (Tables 1 and 2).

In accordance with study report, speed may be either excessive or inappropriate (driving within limits, but too fast for the traffic condition) and it poses a risk by way of shorter time to react for avoiding an accident as well as greater impact if an accident occurs. Riding fast may be influenced by psychological factors, such as beliefs and perceptions associated with speeding, motives for speeding, including impression management, perceived speed and safety, temperamental and attitudinal factors such as sensation seeking and risk-taking, and other factors such as the desire to reduce travel time. 
Table1: Correlates of inclination to speeding Subgroup differences

\begin{tabular}{|l|l|l|l|}
\hline \multirow{2}{*}{$\begin{array}{l}\text { Tendency for thrill } \\
\text { seeking/impulsivity factors }\end{array}$} & $\begin{array}{l}\text { Mean difference in } \\
\text { percentage } \\
\text { SSG }\end{array}$ & NSG & \multirow{\chi}{*}{$\mathbf{2}$} \\
\hline $\begin{array}{l}\text { Liking for chasing } \\
\text { and competing }\end{array}$ & 51 & 17 & $\begin{array}{l}1.21 \\
\mathrm{P}<0.001\end{array}$ \\
\hline $\begin{array}{l}\text { Liking for competing } \\
\text { with friends }\end{array}$ & 58 & 41 & $\begin{array}{l}25.2 \\
\mathrm{P}<0.001\end{array}$ \\
\hline Speeding and overtaking & 55 & 33 & $\begin{array}{l}44.9 \\
\mathrm{P}<0.001\end{array}$ \\
\hline Liking for weaving & 27 & 13 & $\begin{array}{l}25.3 \\
\mathrm{P}<0.001\end{array}$ \\
\hline $\begin{array}{l}\text { Liking for practice of } \\
\text { stunts }\end{array}$ & 22 & 8 & $\begin{array}{l}35.1 \\
\mathrm{P}<0.001\end{array}$ \\
\hline $\begin{array}{l}\text { Speeding even when not } \\
\text { in a hurry }\end{array}$ & 39 & 23 & $\begin{array}{l}25.3 \\
\mathrm{P}<0.001\end{array}$ \\
\hline $\begin{array}{l}\text { Difficulty in stopping at } \\
\text { red signal }\end{array}$ & 23 & 15 & $\begin{array}{l}10.3 \\
\mathrm{P}<0.001\end{array}$ \\
\hline
\end{tabular}

$\mathrm{SSG}=$ Speeding subgroup, NSG=Non- ${ }^{-}$speeding subgroup

Table 2: Triggers/motives for speeding: Subgroup differences

\begin{tabular}{|c|c|c|c|}
\hline \multirow[t]{2}{*}{$\begin{array}{l}\text { Experiences sought as a result } \\
\text { of riding fast }\end{array}$} & \multicolumn{2}{|c|}{$\begin{array}{l}\text { Mean difference in } \\
\text { percentage }\end{array}$} & \multirow[t]{2}{*}{$\chi^{2}$} \\
\hline & SSG & NSG & \\
\hline Sense of power and control & 50 & 32 & $\begin{array}{l}65.1 \\
\mathrm{P}<0.001\end{array}$ \\
\hline Sense of joy & 75 & 50 & $\begin{array}{l}56.9 \\
\mathrm{P}<0.001\end{array}$ \\
\hline Relief from anger & 34 & 19 & $\begin{array}{l}23.7 \\
P<0.001\end{array}$ \\
\hline Relief from boredom & 25 & 15 & $\begin{array}{l}13.4 \\
\mathrm{P}<0.001\end{array}$ \\
\hline Relief from a Couse of distress & 32 & 21 & $\begin{array}{l}13.2 \\
\mathrm{P}<0.001\end{array}$ \\
\hline \multicolumn{4}{|c|}{ Other reason/ triggers for speeding } \\
\hline Competing & 40 & 22 & $\begin{array}{l}36.8 \\
\mathrm{P}<0.001\end{array}$ \\
\hline Presence of girl/boy friend & 23 & 13 & $\begin{array}{l}17.5 \\
\mathrm{P}<0.001\end{array}$ \\
\hline Hurry & 75 & 74 & $\begin{array}{l}0.09 \\
P=0.76\end{array}$ \\
\hline Relief from Traffic & 48 & 44 & $\begin{array}{l}1.01 \\
P=0.31\end{array}$ \\
\hline Drinking & 7.6 & 6.9 & $\begin{array}{l}0.04 \\
\mathrm{P}=0.79\end{array}$ \\
\hline Anger as trigger & 24 & 21 & $\begin{array}{l}0.51 \\
P=0.47\end{array}$ \\
\hline Sadness of mood as trigger & 17 & 14 & $\begin{array}{l}1.4 \\
P=0.22\end{array}$ \\
\hline
\end{tabular}

$\mathrm{SSG}=$ Speeding subgroup, $\mathrm{NSG}=\mathrm{Non}^{-}$speeding subgroup 
The SSG when compared with the NSG reported a significantly higher tendency to anticipate reaching the desired mental states through speeding such as a sense of power, sense of joy, relief from anger, relief from boredom, and relief from what is causing distress. Further, on items associated with thrill-seeking and impulsivity such as speeding even when not in a hurry; liking for chasing, competing, overtaking, lane-hopping, weaving, and practice of stunts; and difficulty in stopping when signal turns red; the SSG reported significantly higher inclination than their counterparts.[3]

\section{SAFETY FEATURES IN EXISTING VEHICLE}

Motorized vehicle like car are equipped with safety features such as airbags, seatbelts and steel cages: motorcycles are quite bare. This leaves riders (and passengers) somewhat vulnerable. Although there are some protective gears like helmet, hand glows but it's surprising to see that only a few numbers of riders prefer to use safety gear.[6][10]

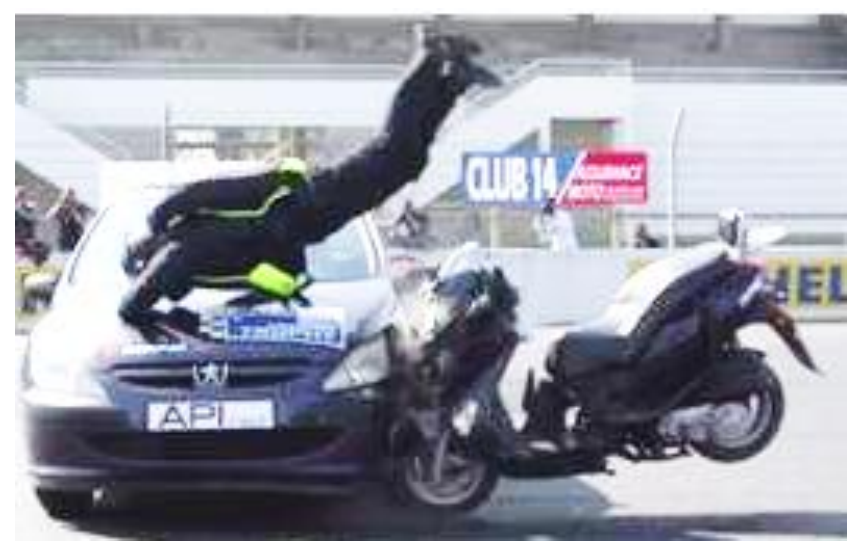

Figure 2: Two Wheeler Crash Image From: Freescale Embedded Beat

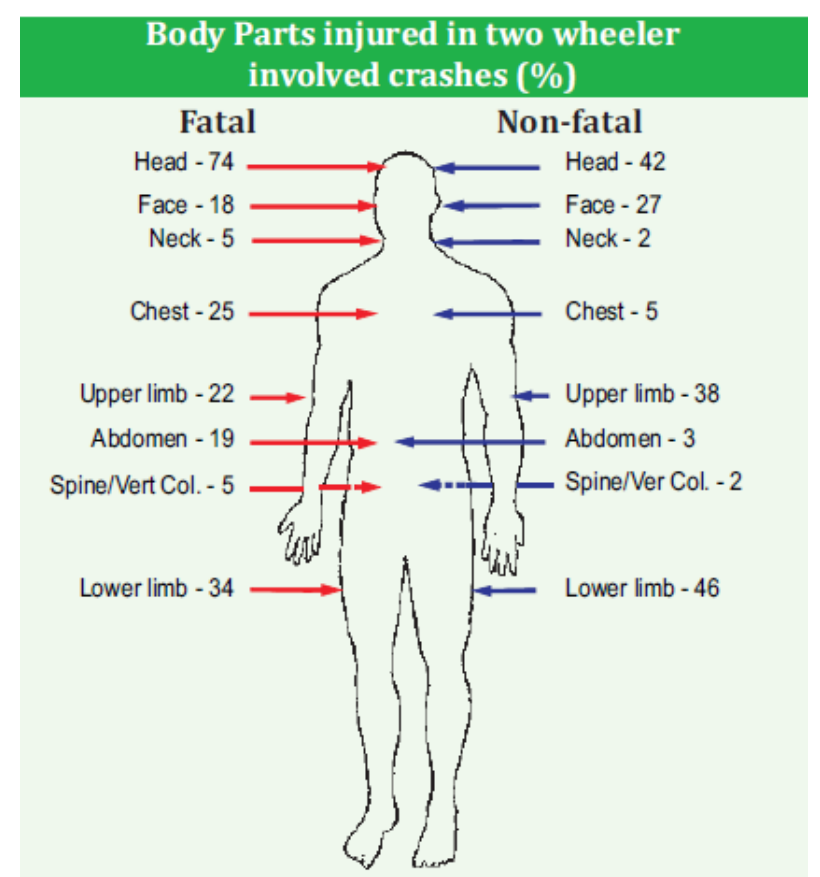

Figure 3: Injury to vital body organs: fatal and nonfatal injuries involved In Two- wheeler accidents 


\section{CONCEPT SAFETY FEATURES}

In this section of paper we will be studying some of the safety features used in cars and based on our understanding of rider's habits and behavior towered the use of safety gear, we will propose new features and modification in existing feature to enhance safety of two wheeler. The suggested feature is described in the basic form of design, there is scope of further improvement and value addition to it. The image of two wheeler, used for showing concept is only for representation purpose and do not have any relationship with base vehicle. [4][10]

\subsection{Feature 1: Seat belt}

A seat belt, also known as a safety belt, is a vehicle safety device designed to secure the occupant of a vehicle against harmful movement that may result during a collision or a sudden stop. A seat belt functions for reducing the likelihood of death or serious injury in a traffic collision by reducing the force of secondary impacts with interior strike hazards

It can be understood that the same situation happens in case of two wheeler, but as there is no seat belt, there is more possibility of throwing away rider and exposing to venerable situation. The study says that most of the fatalities occur because of head injuries, use of seat belt would prevent rider from throwing away to the more vulnerable situation.

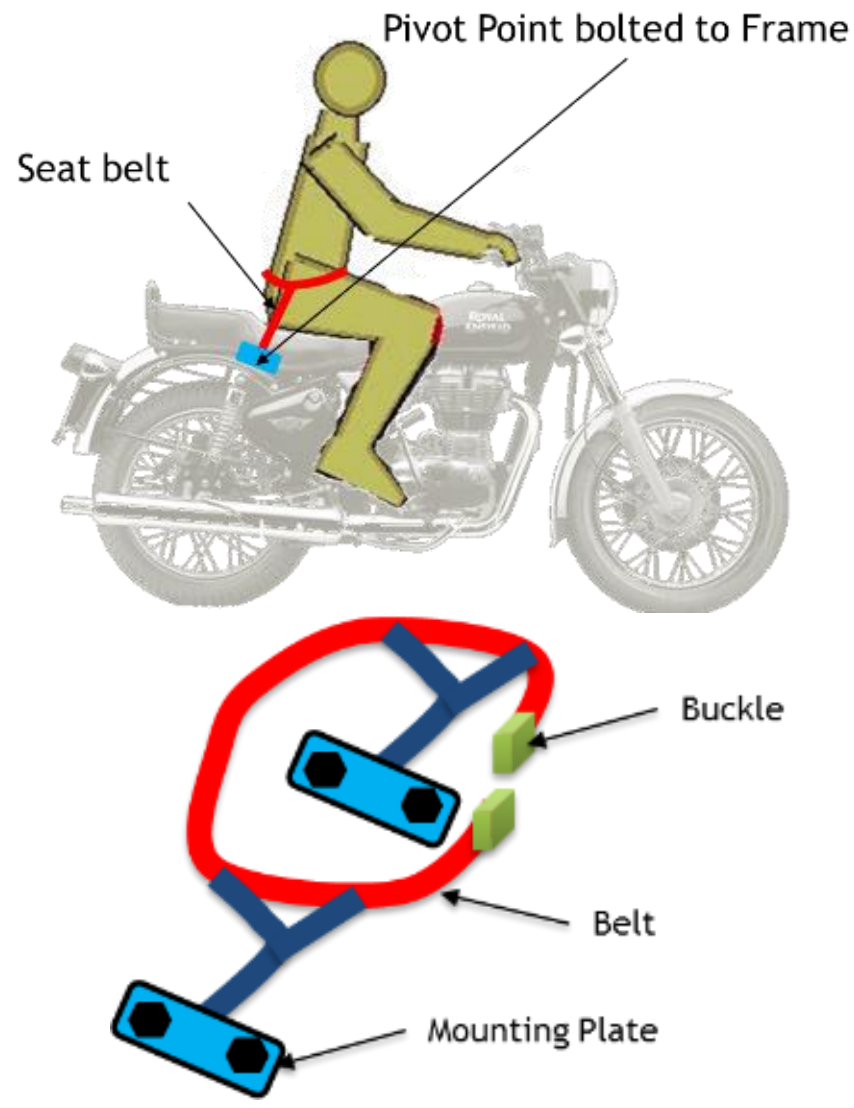

Figure 4: Seat Belt concept and mounting arrangement on motorcycle with Rider (Top) and enlarged view of seat belt concept (Bottom). 
There are some two wheeler which has a seat belt option but, at the same time the seats are also similar to car seats. Because of the closed body type of such two wheelers the acceptance is less compared to the open one. Hence it can be concluded that we need a belt which does not need a big seat like in cars, also it should be small simple and easy to wear.

In the concept of seat belt shown above in Figure. 4, is specially made for two-wheeler application. The belt can be fixed on frame with the help of the bolted joint and buckle in front side of rider. In this case we don't need a big seat with back rest. It will prevent rider from getting thrown away in case of impact.

\subsection{Feature 2: Leg Guard}

Leg Guards are manufactured using metal pipe with different shapes. The basic function of such leg guard is to protect the rider's leg in case of a frontal collision, it does not offer any protection to legs from the side. Leaving the rider exposed to danger in case of a side impact or falling on one side after the impact.

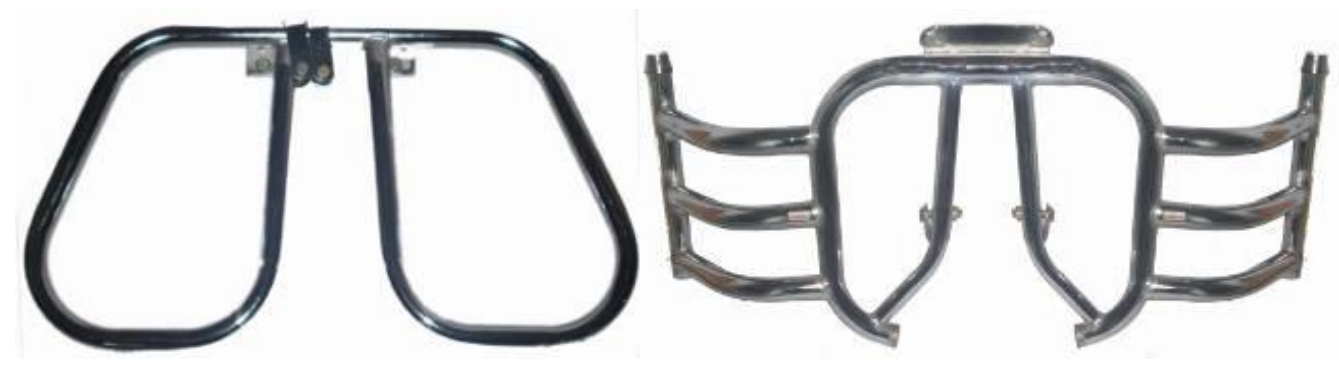

Figure 5: Leg used in motorcycle's in India.

The images shown in Figure. 5 are some of the leg guards mostly used in India. These types of guard are locally made. Manufacturers do not perform any strength check of such components comes in a category of accessories, also the design is not matured enough to give complete protection to rider's leg, there are cases where the rider's legs got injured not because of the accident but because of bend or the damaged leg guard after impact. Such leg guard is one more danger for rider's legs.

The proposed concept shown in Figure. 6 is made out of bend tubes and welded together to form a cage like structure, a bottom member shown in yellow colour is connecting both the side of the guard, which will give additional strength along with protection to foot from bottom side also. 


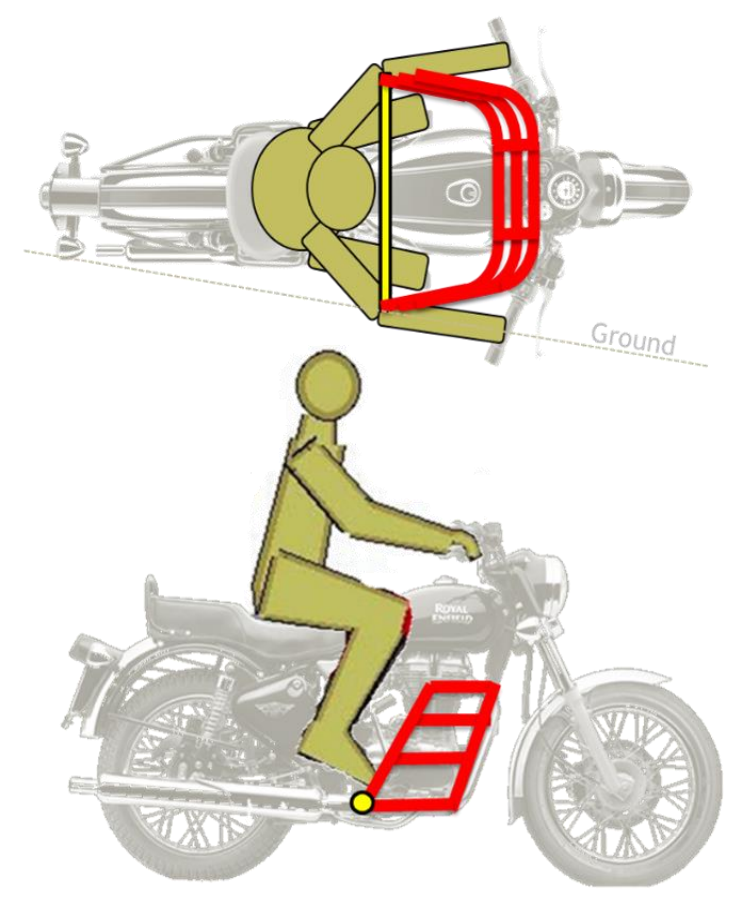

Figure 6: Concept of leg guard with vehicle and rider, top and side view.

The structure can be welded or bolted to the frame, it will give much higher level of protection to leg from the front as well as from the side. The rider's legs are also protected in case if he falls on the side with the motorcycle. The guard design can be further modified considering styling and aesthetics.

\subsection{Feature 3: Back Rest}
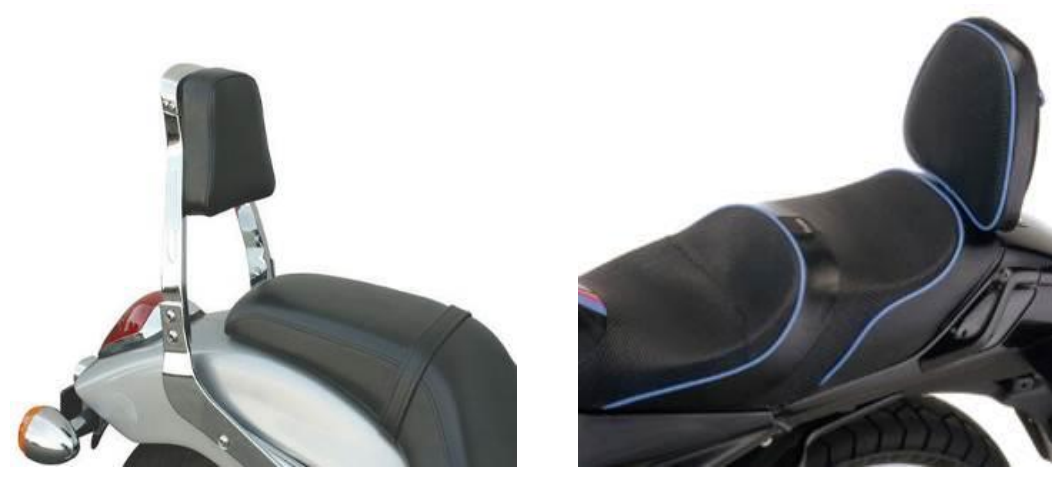

Figure 7: Back Rest used in motorcycle.

A backrest is an addition to the rear of a motorcycle that allows the rider or passenger to recline against it while riding. Alternately, it can serve as an anchor point or support, the riders can take support which helps to prevent fatigue during long ride. The back rest of the rider can also act as support or a holding point for the passenger, which give better balance to a passenger while manoeuvring.

Backrest for cruiser-style motorcycles are usually affixed to the rear fender struts, and are typically made of chrome-plated steel with a foam padded seat back for comfort 
(Figure. 7). Various versions of backrest are available in marked based on the motorcycle type and make, with a variety of arrangement and facilities like sliding type, riser type, and a foldable type.

From the study it is observed that most of the two wheeler users don't prefer to have back rest for the riders not even in the passenger seat. Reason behind this is, it is difficult for the rider to get ON or get OFF from their seat. Most of the female pillion rider wear "Sarees" in India, which makes it difficult for them to sit on the side. Also the space available is limited.

But it is important to have Backrest for the rider as well as pillion rider for better support which is helpful for better control of body in case of impact.

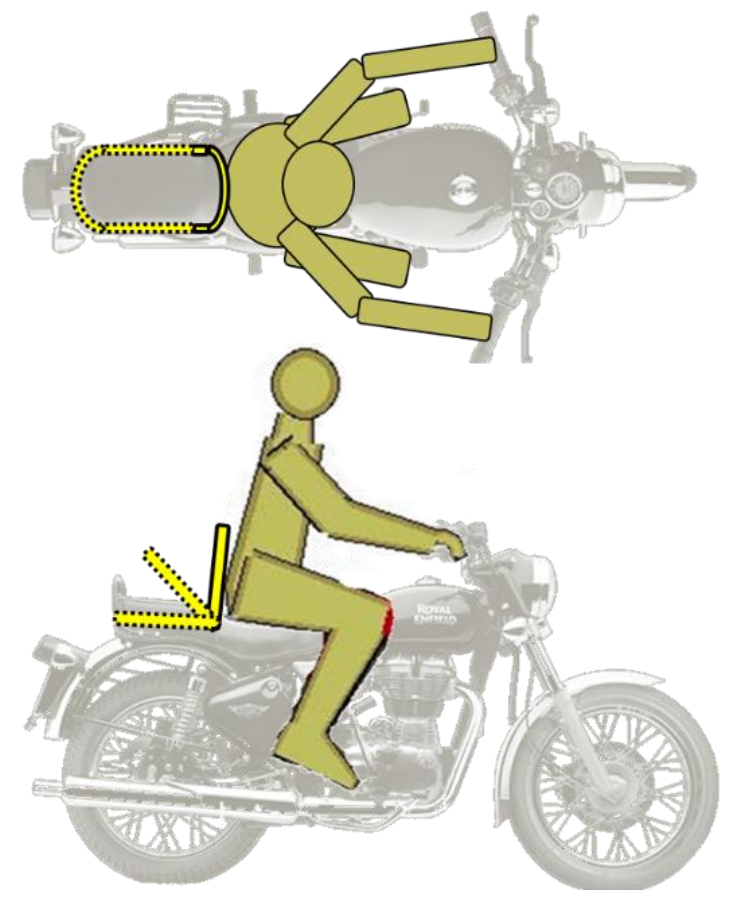

Figure 8: Concept of beck rest mechanism on vehicle with rider in top and side view

The concept of back rest shown in Figure. 8 Can be made out of steel pipes with cushioned back pad, the main advantage of this type back- rest is it can be easily folded back to take the shape of the rear seat. It can be removed and attached to frame with the help of bolted joints as and when required. The concept can further be modified to have some part of the rear seat cushion integrated with back rest which will act as back pad for the rider.

\subsection{Feature 4: Rear Side Indicator}

Turn Signal Lamp or Indicator Lights of a motorcycle provide RED/AMBER colour light on when turning the motorcycle. Turn Signal Lamp / Indicator Light are very useful while riding a bike, mainly at night. It is an essential motorcycle component for safe riding at night / dark. There are different types and designs of Turn Signal Lamp or Indicator Lights used in different brands and models of motorcycles. 


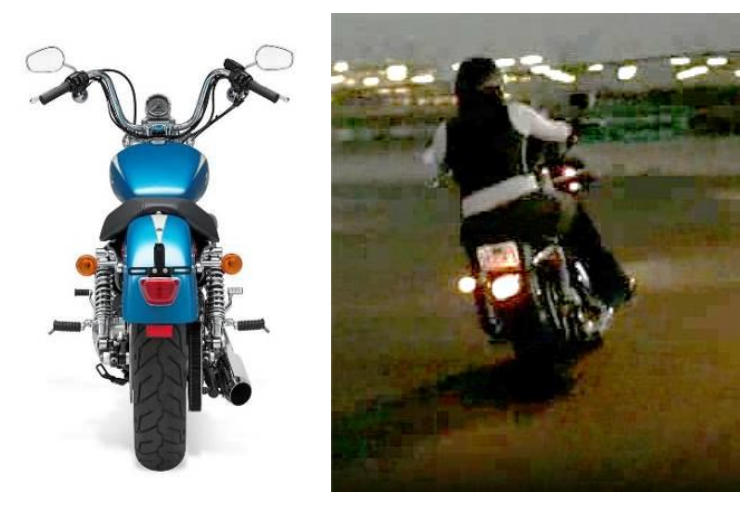

Figure 9. Motorcycle with Rear side indicator. Side indicator ON in other image while turning.

Most motorcycles have two sets of Turn Signal Lamp or Indicator Lights, both in the front and at the back. The indicator switch, normally on the Left Hand Side, has 3 positions - OFF, Left and Right. The Left or Right Indicators help the people in front or rear to understand to which side of the road you will be turning. In many countries, motorcycle manufacturers are required to use a motorcycle Turn Signal Lamp or Indicator Light modulator that oscillates the intensity of light or blinking indicator lights on side vehicle will turn (Figure. 9).

Two Wheeler Indicator specifies the direction of bike riding for road safety purposes. Hence, they require to have Optimum visibility, long working life, excellent luminosity. The indicator body is usually flexible too as the joint between bulb holders and mounting point is made of rubber or other flexible material.

In the proposed concept the indicators will perform one more function in addition to all other conventional functions. That is to take side load of the vehicle and riders in the situation vehicle falls down due to impact/accident or any other reason.

As we know any object can be supported on three points, a similar concept is applicable for the two wheeler, also, consider a situation where a two wheeler comes across an accident and it's going to fall on one side with the rider and Passenger seating on it.

If we look at two wheeler carefully from the side and from the back or front, we can see there are three points which are extended out of the vehicle those will come in contact with the ground first. These points are end of the handle bar, foot rest and rear indicator.

Most of the two wheelers have a short length indicator that too with soft and flexible assembly, hence those types of indicator cannot be considered as the third point to support the vehicle. In the proposed concept the indicators are extended outside so that it will cover pillion rider's leg. Also the mechanism is so designed that during horizontal position it will be flexible, such that it will not get stuck with any passing vehicle or pedestrian, but in case of falling vehicle the indicator will become rigid and provide support to vehicle. 

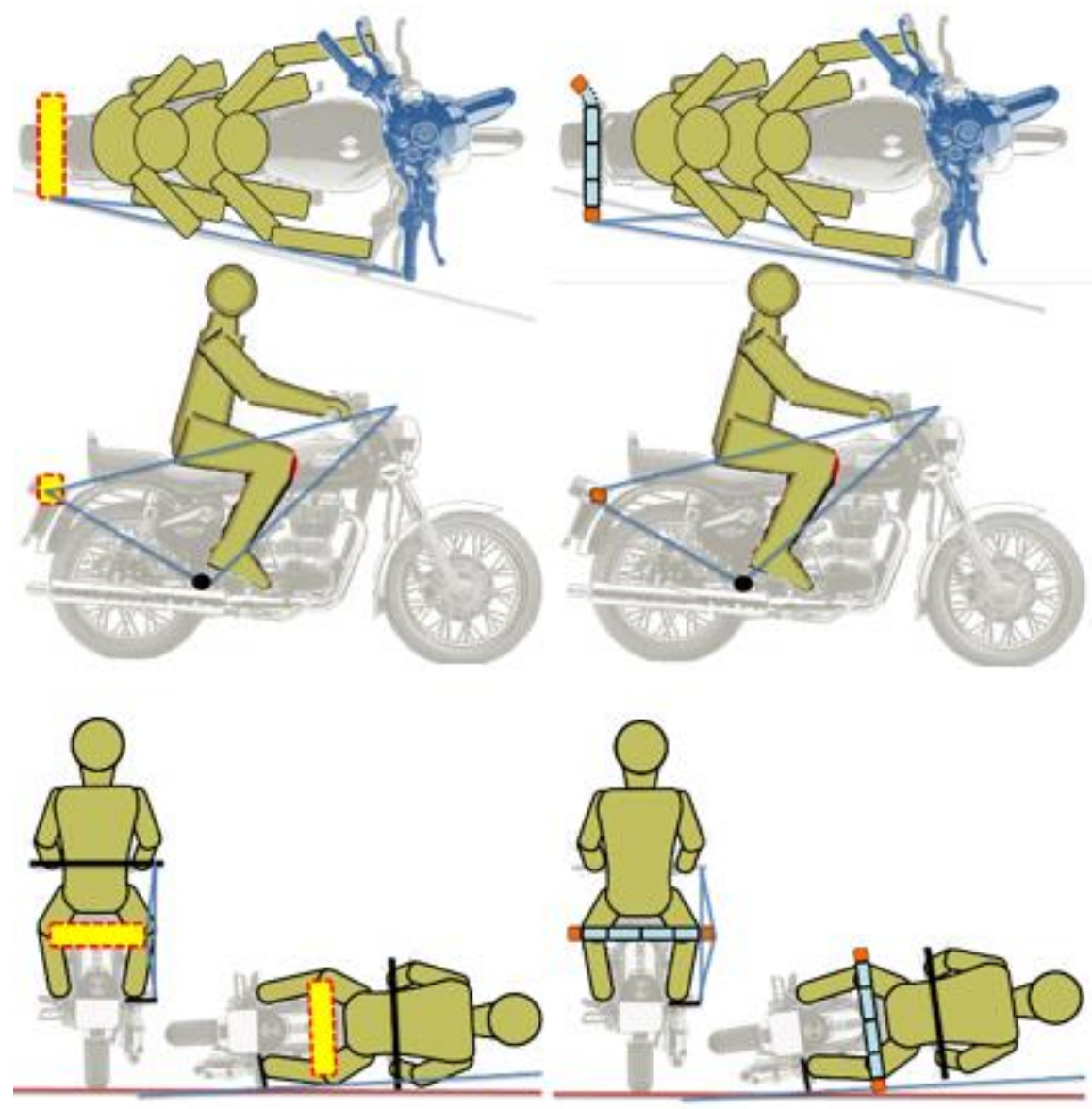

Figure 10. Comparative Image of motorcycle with conventional Indicator and concept indicator showing safe zone by blue lines in Top, side and back view

Figure.10 shows comparison of conventional indicator design and concept indication design, a triangle formed by three points on the vehicle is shown by the blue line, it can be seen that in case of vehicle fitted with conventional indicator, the leg of pillion rider and rider are less protected or exposed to come in contact with the ground. If the vehicle fall at speed and slide on the road it will result in serious injuries to both rider and pillion, also the entire weight of the vehicle will come on the rider's leg as there is no other support point.

While in case of the vehicle fitted with concept indicator, the footrest and the indicator will first come in contact with the ground, keeping a good amount of space between the ground and the rider's leg. In this case the rider's legs will not be locked between the ground and vehicle, also the first impact after falling will be taken by the three points preventing the rider from serious leg injuries. This will also increase the safe zone for pillion riders. Making motorcycle much safer. 


\section{CONCLUSION}

From the study it is evident that even though there are good legislation available in middle income countries, but their enforcement is not to the mark, except for few metropolitan cities. Also the peoples are not educated on the importance of road safety and safety features, the majority of young population do not want to use safety gear because of their attitude or psychological factors, such as beliefs and perceptions associated with speeding.

In order to minimize two- wheeler fatalities. Local authorities need to take strong steps such as.

- Stringent check.

- Empower police to check safety gears.

- Ensure use of road safety devices (helmets, belts, etc.)

- Heavy penalty for drunken driving, not using safety gears and speeding.

The two wheeler manufactures can also design safer vehicle and the authorities should include a safety feature as a mandatory requirement for the type approval.

The features suggested in this paper simple and easy to implement without doing major change in vehicle, it will also help in reducing saviour injuries. This was an attempted aimed to make Two-wheeler a safer mode of transportation in society.

\section{REFERENCES}

[1] World Health organization, Global status report on road safety 2013 Supporting a decade of action ISBN $978924 \mathbf{1 5 6 4 5 6}$ 4, 14 March 2013 http://www.who.int/iris/bitstream/10665/78256/1/9789241564564_eng.pdf

[2] MADHAV PAI, ANJALI MAHENDRA, RANJIT GADGIL, SHWETA VERNIKAR, REBECCA HEYWOOD, RADHA, EMBARQ Network, Motorized Two-Wheelers in Indian Cities, 25 Sept 2014 http://www.embarq.org/sites/default/files/Motorized-two-wheelers-indian-cities-pune25-9-14.pdf

[3] RAJEEV J. MICHAEL, MANOJ K. SHARMA, SEEMA MEHROTRA, HUMERA BANU, RAJESH KUMAR, PAULOMI M. SUDHIR, NEELIMA CHAKRABARTHY, National Institute of Mental Health and Neuro Sciences (NIMHANS)Industrial Psychiatry Journal, Inclination to speeding and its correlates among two-wheeler riding Indian youth, December 2014

http://www.industrialpsychiatry.org/temp/IndPsychiatryJ232105-2559491_070634.pdf

[4] ERIC SCHAAL, cheatsheet,7 New Motorcycles With Innovative Safety Features, 30 March 2014, http://www.cheatsheet.com/automobiles/7-new-motorcycles-withinnovative-safety-features.html/?a=viewall

[5] DR. POONAM MITTAL, DR. RENUKA GARG, 16th Road Safety on Four Continents Conference Beijing China, Study Of Behavior Of Two Wheelers Drivers Towards Helmet Wearing, Talking On Cell Phone While Driving And Driving With Many Pillion Riders: 15-17 May 2013: http://vti.divaportal.org/smash/get/diva2:760020/FULLTEXT01.pdf

[6] DR. GURURAJ, NIMHANS Bisp Fact Sheet: Two Wheelers Safety: Published By Nimhans with Support from World Health Organization, India Office, 17 Nov 2014 www.nimhans.kar.nic.in/epidemiology/bisp/fs5.pdf 
[7] MD NAZMUL KARIM. WHO fact sheet, Road safety status in the WHO SouthEast Asia Region 2013, March 2013,

http://www.searo.who.int/entity/disabilities_injury_rehabilitation/topics/fact_sheet_road _safety_final.pdf

[8] WHO PUBLICATIONS, Strengthening Road Safety Legislation: A practice and resource manual for countries 2013

http://apps.who.int/iris/bitstream/10665/85396/1/9789241505109_eng.pdf?ua=1

[9] Images used for concept creation of Royal Enfield classic bullet Electra:

http://www.topspeed.com/motorcycles/motorcycle-reviews/royal-enfield/2014-royalenfield-bullet-electra-ar164137.html

[10] Figure 2: Two wheeler crash image from: Freescale embedded beat HTTP://BLOGS.FREESCALE.COM/WP-CONTENT/UPLOADS/2010/12/UNTITLED.JPG 